\section{Effects of the injection grout Silica sol on bentonite}

\author{
Michael Holmboe*,a, Susanna Wold ${ }^{\mathrm{a}}$, Torbjörn Petterson ${ }^{\mathrm{b}}$ \\ KTH School of Chemical Science and Engineering, \\ Division of Nuclear Chemistry ${ }^{a}$ and Fibre Technology ${ }^{b}$ \\ Royal Institute of Technology, SE-100 44 Stockholm, Sweden \\ *Corresponding author: \\ E-mail address: holmboe@kth.se (M. Holmboe) \\ Phone: +46-(0)8-7908789 \\ Fax: +46-(0)8-7908772.
}

Keywords: Bentonite, Bentonite colloids, Silica sol, Silica colloids, Colloidal stability, Colloid interactions.

\begin{abstract}
Silica sol, i.e., colloidal $\mathrm{SiO}_{2}$, may be used as a low-pH injection grout for very fine fractures in the construction of deep geological repositories for radioactive waste in Sweden and in Finland. If the bentonite barrier encounters $\mathrm{SiO}_{2}$-colloid particles under conditions favorable for aggregation, there is concern that it will modify the bentonite barrier at the bentonite/bedrock interface. In this study qualitative experiments were performed with mixed dispersions of $\mathrm{SiO}_{2}$-colloids and bentonite or homo-ionic $\mathrm{Na} / \mathrm{Ca}$-montmorillonite. Samples were prepared at different colloid concentrations and treated under various conditions such as low and high ionic strength (0.3 M $\mathrm{NaCl}$ ), as well as dehydration and redispersing. Free swelling and settling experiments were performed in order to qualitatively compare the conditions in which $\mathrm{SiO}_{2-}$ colloids affect the bulk/macro properties of bentonite. In order to study specific $\mathrm{SiO}_{2}$-colloid/montmorillonite interactions and preferred type of initial aggregation, dilute dispersions of homo-ionic montmorillonite dispersions mixed with varying concentrations of $\mathrm{SiO}_{2}$-colloids were prepared and selected samples were characterized by PCS, SEM/EDS, AFM and PXRD. The results from this study show that bentonite and montmorillonite particles can be modified by $\mathrm{SiO}_{2}$-colloids when mixed in comparable amounts, due to dehydration or high ionic strength. Some indications for increased colloidal stability for the $\mathrm{SiO}_{2}$ colloid modified clay particles were also found. From the AFM investigation it was found that initial attachment of the $\mathrm{SiO}_{2}$-colloids in $\mathrm{Na}^{+}$dominated samples seemed to occur on the edges of the montmorillonite layers. In $\mathrm{Ca}^{2+}$ dominated samples not subjected to excess $\mathrm{NaCl}, \mathrm{SiO}_{2^{-}}$ colloid sorption onto the faces of the montmorillonite layers was also found. In all, contact between the bentonite barrier and ungelled Silica sol should preferably be avoided.
\end{abstract}

\section{Introduction}

During the construction phase of the deep geological repositories for nuclear waste in Sweden and Finland, the hydraulic conductivity of the bedrock must be controlled and kept at a low level which is to be accomplished by the use of suitable injection grouts. A potential candidate for very fine fractures is the gel formed from injected Silica sol (hydrolyzed $\mathrm{SiO}_{2}-$ colloids), using $\mathrm{NaCl}$ as an accelerator. Compared with other conventional cement-based injection grouts, silica sol has the ability to seal finer fractures with apertures of $10-170 \mu \mathrm{m}$, and gives rise to leachate water with $\mathrm{pH}<11$ (Bodén and Sievänen, 2005, Funehag, 2008, Hölttä, 2008). As many other countries, Sweden and Finland also plan to use compacted bentonite as a barrier in their multi-barrier concepts for storage of nuclear waste. So far the effects and possible interactions of the hydrolyzed silica sol particles with bentonite under repository conditions have not been well studied. Regardless of how or when the bentonite barrier may be subjected to $\mathrm{SiO}_{2}$-colloids, the effect of deposition of large quantities of hydrolyzed $\mathrm{SiO}_{2}$ into the immediate vicinity of the bentonite barrier should be investigated. In this study the general effects of $\mathrm{SiO}_{2}-$ colloids on bulk/macro properties of bentonite is investigated as well as the initial and preferred form of montmorillonite/ $\mathrm{SiO}_{2}$-colloid aggregation in mixed montmorillonite/ $\mathrm{SiO}_{2}$-colloid systems.

\subsection{Background}

During excavation of the host rock silica sol is planned to be pumped into drilling holes or fractures, directly after mixing with an accelerator composed of 10 weight $\% \mathrm{NaCl}$ in a 5:1 ratio of $\mathrm{SiO}_{2}$-colloids to $\mathrm{NaCl}$. This procedure induces rapid colloid aggregation and gel formation in the boreholes/fractures usually within 1 hour and reduces the hydraulic conductivity and groundwater inflow to desired levels $(<1 \mathrm{~L}$ per minute and $60 \mathrm{~m}$ tunnel, Funehag, 2008). Since a full deterministic description of the fracture zones often is very difficult, grouting is always subjected to uncertainties. If the injected $\mathrm{SiO}_{2}$-colloids would encounter large water-bearing fractures, dilution with decreasing aggregation rate and increasing gel time is probable. The final extent 
and methodology of grouting is never determined $a$ priori, but worked out along the way during the construction of the repository (Emmelin et al. 2007).

The probability however of the hydrolyzed $\mathrm{SiO}_{2}{ }^{-}$ colloids encountering the bentonite barrier is considered to be low since most expected grouting operations will take place before deposition of the bentonite barriers. If the bentonite barrier would encounter the hydrolyzed $\mathrm{SiO}_{2}$-colloids under conditions favorable for aggregation during the construction phase or later, the expected properties of the bentonite barrier at the bentonite/bedrock interface may be altered. This may affect future colloid generation and bentonite erosion in the event of intrusion of glacial melt water, which is one of the most critical scenarios for the bentonite barrier since mass loss can be substantial under certain conditions (Le Bell, 1978, Laaksoharju and Wold, 2005, Neretnieks et al. 2009). On the other hand, if the gel from Silica sol deposited in the fracture zones proves to be stable towards time and changing groundwater conditions, erosion of bentonite may be inhibited. The long-time behavior and stability of the silica sol gel itself is not well known, but it is generally assumed that it will be in operation and remain stable for 100 years. Release of the primary hydrolyzed $\mathrm{SiO}_{2}$-colloids from the gel is expected to be small (Hölttä et al. 2009), especially at elevated ionic strength. The solubility the amorphous $\mathrm{SiO}_{2}$-particles are expected to be approximately one magnitude higher than quartz (Gunnarsson and Arnórsson, 2000, Karnland et al. 2007). Thus with changing groundwater conditions, the $\mathrm{SiO}_{2}$ gel would be more likely to undergo solubility-precipitation reactions compared to similar crystalline minerals present in the bedrock.

In general, under low ionic strength groundwater conditions direct aggregation between hydrolyzed $\mathrm{SiO}_{2}$-colloids and bentonite particles would not be expected due to the unfavorable charge conditions between the negatively charged particles. However, when subjected to dehydration or elevated ionic strength, especially in the presence of $\mathrm{Ca}^{2+}$ (Iler, 1979, Lee and Moon, 2004, Kinsela et al. 2010), the $\mathrm{SiO}_{2}$-colloids will unavoidably aggregate and coalesce into larger particles and aggregates, either with bentonite or with other $\mathrm{SiO}_{2}$-colloids.

Compared with montmorillonite colloids, hydrolyzed $\mathrm{SiO}_{2}$-colloids show much higher colloid stability at slightly alkaline conditions, even under relatively high ionic strength (Iler, 1979). Thus, if the hydrolyzed $\mathrm{SiO}_{2}$-colloids prove to be reactive towards montmorillonite, an increase in colloid stability of the modified montmorillonite/ $/ \mathrm{SiO}_{2}$-colloid particles compared to montmorillonite particles is probable. When aggregating homogeneously, either under high ionic strength or because of dehydration, the hydrolyzed $\mathrm{SiO}_{2}$-colloids can form covalent siloxane bonds through the reactive siloxane surface groups (Iler, 1979). In the presence of bentonite, the same type of irreversible reaction may occur along the edges of the montmorillonite layers due to the silanol bonds at the montmorillonite edges. If the hydrolyzed $\mathrm{SiO}_{2}$-colloids show a large tendency for heterogeneous aggregation, i.e., react and aggregate irreversibly with the edges of the montmorillonite particles, both the physical/macro properties (swelling pressure, rheology) and the colloidal properties of the silica-modified montmorillonite particles may be drastically different from those of unmodified montmorillonite. With regards to this, there is concern that $\mathrm{SiO}_{2}$-colloids may considerably change the bulk properties and colloidal behavior of bentonite.

In summary, several hypothetical scenarios of the hydrolyzed $\mathrm{SiO}_{2}$-colloids encountering the bentonite (or vice versa) exist: i) Unforeseen $\mathrm{SiO}_{2}$-colloid transport due to underestimation of the hydraulic capacity of the fracture zones and inadequate gel formation during grouting. ii) Transport of bentonite into fractures grouted with $\mathrm{SiO}_{2}$-colloids, in the event of bentonite erosion. iii) Solubility-precipitation reactions of secondary $\mathrm{SiO}_{2}$-particles with bentonite.

In this study the general effects of $\mathrm{SiO}_{2}$-colloids on the bulk/macro properties of bentonite and more specifically the initial and preferred form of montmorillonite $/ \mathrm{SiO}_{2}$-colloid attachment in mixed montmorillonite/ $\mathrm{SiO}_{2}$-colloid systems are investigated. Qualitative bulk/macro experiments and colloid/aggregate characterization of mixed bentonite $/ \mathrm{SiO}_{2}$-colloid systems has been performed 
using Photon correlation spectroscopy (PCS), Atomic force microscopy (AFM), Scanning electron microscopy (SEM) and Powder X-ray diffraction (PXRD). In order to determine the possible conditions under which aggregation between montmorillonite and $\mathrm{SiO}_{2}$-colloids would be possible, different screening aggregation experiments were performed under four conditions: i) Low ionic strength, ii) High ionic strength, iii) Dehydration (drying), and iv) High ionic strength and dehydration. Condition $i$ ) was taken as the reference case, since montmorillonite/ $\mathrm{SiO}_{2}$-colloid aggregation under ambient conditions is not expected. The high ionic strength conditions were set according to the corresponding $\mathrm{NaCl}$ concentration $(0.3 \mathrm{M})$ used in injection experiments in Äspö Hard Rock Laboratory, Sweden. Would the bentonite barrier not be fully water-saturated when coming into contact with the $\mathrm{SiO}_{2}$-colloids, either due to heat evolving from the nuclear fuel or due to slow water-saturation of the bentonite barrier, aggregation due to dehydration may also be a plausible scenario. This is because the $\mathrm{SiO}_{2}$ colloids aggregate irreversibly if subjected to a water content below 35 weight $\%$, according to the manufacturer.

\section{Material and Methods}

\subsection{Materials}

Silica sol is a commercially available product with several different applications. As an injection grout, silica sol has successfully been applied to several tunnel constructions in Sweden. The specific silica sol used in this study, Meyco MP 320 (EKA Chemicals, Sweden) has been tested as an injection grout in situ at Äspö Hard Rock Laboratory, Sweden and in Olkiluoto, Finland. This product consists of hydrolyzed and negatively charged $\mathrm{SiO}_{2}$-colloids and has a particle size ranging from 3-70 nm, with an average size of approximately $15 \mathrm{~nm}$. The bentonite used in this study was MX-80 Wyoming bentonite with a montmorillonite content of approximately $83 \%$. The exchangeable cations for this bentonite are approximately: $75 \% \mathrm{Na}^{+} ; 17 \% \mathrm{Ca}^{2+} ; 7 \% \mathrm{Mg}^{2+} ; 2 \%$ $\mathrm{K}^{+}$. The homo-ionic sodium and calcium montmorillonites used were purified MX-80 Wyoming bentonite according to Karnland et al., 2006. The CEC for MX-80 and the purified Namontmorillonite measured by a modified $\mathrm{Cu}$ (II)-trien method is $\sim 0.75$ and $\sim 0.85 \mathrm{meq} / \mathrm{g}$, respectively (Karnland et al., 2006).

\subsection{Method}

\subsubsection{Free swelling and settling experiments with bentonite}

Free swelling and settling experiments were performed in order to qualitatively compare the conditions in which $\mathrm{SiO}_{2}$-colloids affect the bulk/macro properties of bentonite. The experiments were performed with mixed bentonite and $\mathrm{SiO}_{2}-$ colloid dispersions under different conditions representing the four postulated scenarios, i) low ionic strength, ii) high ionic strength, iii) dehydration, and iv) high ionic strength and dehydration. In the free swelling experiments, $1 \mathrm{~g}$ of bentonite was allowed to expand in the presence of varying amounts of $\mathrm{SiO}_{2}$-colloids, with or without $\mathrm{NaCl}$ addition to a total volume of $100 \mathrm{~mL}$ for 2 months. The final volume and appearance of the swelling bentonite$\mathrm{SiO}_{2}$-colloid mixtures were inspected visually and photographed. The samples were first prepared in 10 $\mathrm{mL}$ of water with $0 ; 0.1 ; 0.5 \mathrm{~g} \mathrm{SiO}_{2}$-colloids (with or without addition of $\mathrm{NaCl}(\mathrm{aq})$ ). Water and $\mathrm{SiO}_{2}-$ colloids were added slowly in order to minimize dispersal of bentonite colloids. The dehydrated bentonite samples were mixed with $10 \mathrm{~mL} \mathrm{SiO}_{2}$ colloids (with or without addition of $\mathrm{NaCl}$ ) and then dried at $60^{\circ} \mathrm{C}$. Samples subjected to $\mathrm{NaCl}$ addition were kept for two days in $10 \mathrm{~mL} 300 \mathrm{mM} \mathrm{NaCl}$. Thereafter the samples were finally diluted with Milli-Q water to a final volume of $100 \mathrm{~mL}$ giving a final $\mathrm{NaCl}$ concentration of $30 \mathrm{mM}$. This procedure was necessary because any changes in the colloidal stability and settling of bentonite would not be observed at high ionic strengths corresponding to 300 $\mathrm{mM} \mathrm{NaCl}$. The settling experiment was performed by dispersing the same samples and monitoring the settling behavior visually. In these types of experiments, two distinct types of settling processes, called free and structural settling, can usually be distinguished. In free settling, the rate of particle aggregation is significantly lower than the rate of settling due to large particle size or repulsion between particles/colloids. This settling behavior results in independent settling of the dispersed particles and a diffuse mud-line. With time, a relatively dense sediment forms at the bottom of the vessel. In structural settling, induced by addition of electrolyte or a change in $\mathrm{pH}$, the rate of particle/colloid 
aggregation is faster than the settling rate. At first the dispersion becomes more opaque, due to aggregation and formation of a volume-filling aggregate network. After some time, the network of aggregated particles breaks down, probably due to compaction and rearrangement of the aggregates, and a sharp interface (mud-line) between a clear supernatant and the montmorillonite phase is seen, as the latter is pulled down by gravitational forces. Within a subsequent period (usually weeks), a constant sediment volume is eventually formed. In the region of this transition point, where the rate of colloid aggregation and settling are comparable, even larger final sediment volumes are usually seen. Table 1 summarizes the conditions for the free swelling and settling experiments.

Table 1. Experimental conditions and treatments used in the free swelling and settling experiments. Note the different orders.

\begin{tabular}{l|ccc} 
Sample treatment & \multicolumn{3}{c}{$\mathrm{m}_{\mathrm{Bentonite}}: \mathrm{m}_{\mathrm{SiO}_{2}}(\mathrm{~g})$} \\
\hline Untreated & $1: 0$ & $1: 0.1$ & $1: 0.5$ \\
$\mathrm{NaCl}$ addition $\left(\mathrm{SiO}_{2}+\mathrm{NaCl}\right)$ & $1: 0$ & $1: 0.1$ & $1: 0.5$ \\
$\mathrm{NaCl}$ addition $\left(\mathrm{NaCl}+\mathrm{SiO}_{2}\right)$ & $1: 0$ & $1: 0.1$ & $1: 0.5$ \\
Dehydrated & $1: 0$ & $1: 0.1$ & $1: 0.5$ \\
$\mathrm{NaCl}$ addition + dehydrated & $1: 0$ & $1: 0.1$ & $1: 0.5$ \\
dehydrated $+\mathrm{NaCl}$ addition & $1: 0$ & $1: 0.1$ & $1: 0.5$
\end{tabular}

\subsubsection{Montmorillonite/ $\mathrm{SiO}_{2}$-colloid interactions}

In order to study specific $\mathrm{SiO}_{2-}$ colloid/montmorillonite interactions and possible aggregation, dilute dispersions of homo-ionic Namontmorillonite dispersions mixed with varying concentrations of $\mathrm{SiO}_{2}$-colloids were prepared, photographed and selected samples were characterized by PCS, SEM/EDS, AFM and PXRD. Table 2 summarizes these mixed dispersions. In the AFM investigation, samples of homo-ionic Camontmorillonite were also studied. The waterdehydrated samples were first dried and then redispersed with water to the initial volume.

\subsubsection{Size and concentration measurements using PCS}

The mixed dispersions of $\mathrm{Na} / \mathrm{Ca}$-montmorillonite and $\mathrm{SiO}_{2}$-colloids were measured with dynamic light scattering using photon correlation spectroscopy (PCS) approximately one month after preparation. Prior to each measurement, the sample vials were shaken manually in order to disperse all particles. The samples were then left to stand for 1 hour to ensure settling of larger particles. Except for a few of the most concentrated and water-dehydrated samples, the samples were measured undiluted. The PCS instrument used was a BI-90 Particle Sizer, (Brookhaven Instruments Inc.) with a $488 \mathrm{~nm}$ laser and fixed scattering angle of $90^{\circ}$. This technique enables the hydrodynamic diameter of monodisperse colloids and particles of size 10-2000 $\mathrm{nm}$ to be measured. The output signal, given in counts/s, is dependent on colloid concentration as well as size. Hence for polydisperse colloids or dispersions with bimodal size distributions as in this study, this technique can only be used qualitatively in order to compare similar dispersions, since larger particles will dominate both the PCS count rate and the size estimation.

Table 2. Summary of the mixed $\mathrm{SiO}_{2}$-colloid/montmorillonite dispersions.

\begin{tabular}{|c|c|c|c|c|}
\hline \multicolumn{3}{|c|}{$\mathrm{m}_{\mathrm{Na} / \mathrm{Ca}-\mathrm{mont}}: \mathrm{m}_{\mathrm{SiO} 2}(\mathrm{wt} \%)$} & \multirow{2}{*}{$\frac{\mathrm{NaCl}(\mathrm{M})}{-}$} & \multirow{2}{*}{$\begin{array}{c}\text { Dehydrated } \\
\mathrm{x}\end{array}$} \\
\hline & 1 & $0.1: 0.0$ & & \\
\hline A & 2 & 0.1:0.0 & 0.3 & - \\
\hline & 3 & $0.1: 0.0$ & 0.3 & $\mathrm{x}$ \\
\hline \multirow{3}{*}{ B } & 1 & $0.1: 0.01$ & - & $\mathrm{x}$ \\
\hline & 2 & $0.1: 0.01$ & 0.3 & - \\
\hline & 3 & $0.1: 0.01$ & 0.3 & $\mathrm{x}$ \\
\hline \multirow{3}{*}{$\mathrm{C}$} & 1 & $0.1: 0.1$ & - & $\mathrm{x}$ \\
\hline & 2 & 0.1:0.1 & 0.3 & - \\
\hline & 3 & 0.1:0.1 & 0.3 & $\mathrm{x}$ \\
\hline \multirow{3}{*}{$\mathrm{D}$} & 1 & 0.1:0.4 & - & $\mathrm{x}$ \\
\hline & 2 & 0.1:0.4 & 0.3 & - \\
\hline & 3 & 0.1:0.4 & 0.3 & $\mathrm{x}$ \\
\hline \multirow{3}{*}{$\mathrm{E}$} & 1 & 0.0:0.4 & - & $\mathrm{x}$ \\
\hline & 2 & 0.0:0.4 & 0.3 & - \\
\hline & 3 & 0.0:0.4 & 0.3 & $\mathrm{x}$ \\
\hline
\end{tabular}

\subsubsection{Particle size and elemental analysis with SEM/EDS}

A JEOL JSM9460LV scanning electron microscope (SEM), fitted with electron dispersive spectroscope (EDS), was used to study larger aggregates from the water-dehydrated and redispersed mixed montmorillonite/ $\mathrm{SiO}_{2}$-colloid dispersions shown in Table 2 . The SEM samples were prepared by spincoating a diluted aliquot of the dispersions onto a carbon tape. Since dehydration (drying) was one of the hypothetical scenarios for montmorillonite/ $/ \mathrm{SiO}_{2}-$ colloid interactions, drying effects during the AFM 
sample preparation was not seen as a problem. Elemental analysis by EDS was performed on aggregates and particles in order to verify the $\mathrm{Al}$ and $\mathrm{Si}$ contents. By comparing the $\mathrm{Al} / \mathrm{Si}$ ratios it was possible to calculate the relative abundance of montmorillonite to $\mathrm{SiO}_{2}$-colloids by comparing the $\mathrm{Al} / \mathrm{Si}$ ratio obtained by EDS with the theoretical $\mathrm{Al} / \mathrm{Si}$ ratio, which was calculated from the mass of montmorillonite and the mass of added $\mathrm{SiO}_{2}$ for the specific dispersion.

\subsubsection{Montmorillonite/SiO ${ }_{2}$-colloid characterization using AFM}

An AFM investigation was performed on selected samples from Table 2 in order to study individual small montmorillonite/ $\mathrm{SiO}_{2}$-colloid particles and their preferred way of aggregation under dehydration. The AFM measurements were performed in dry state in tapping mode (unless otherwise stated) with a Veeco Multimode IIIA AFM with an E-scanner. DP14/SCD/AIBS cantilevers were used (MikroMasch) with resonance frequency $160 \mathrm{kHz}$, spring constant $5.7 \mathrm{~N} / \mathrm{m}$ and tip radius $<7 \mathrm{~nm}$. The AFM samples were prepared by drying an aliquot of a diluted dispersion (1:100) onto a freshly cleaved mica substrate at ambient temperature.

\subsubsection{Basal spacing measurements using PXRD}

The intensities and widths of the $00 l$ XRD peaks are known to depend on the average crystallite (particle) size (Moore and Reynolds, 1997). In order to investigate whether the size and basal spacings $\left(d_{00 l}\right)$ of the montmorillonite layers in bentonite were affected by aggregation with $\mathrm{SiO}_{2}$-colloids, PXRD measurements were performed of dehydrated bentonite $/ \mathrm{SiO}_{2}$-colloid samples as a function of varying $\mathrm{SiO}_{2}$ content. The samples were prepared by mixing 1 weight $\%$ bentonite with $\mathrm{SiO}_{2}$-colloids in ratios of 100:0, 80:20, 50:50, 20:80, 0:100 (bentonite: $\mathrm{SiO}_{2}$-colloids). The samples were dried, ground and saturated at $85 \mathrm{RH} \%$ by adsorption for 2 months by equilibrating with a saturated $\mathrm{KCl}$ solution. The measurements were performed in reflection mode (Bragg-Brentano geometry) using a PANalytical X'Pert PRO instrument with $C u K_{\alpha}$ radiation and with a programmable divergence slit. The samples were covered by a Kapton film to avoid drying effects and scanned from $3-25^{\circ}(2 \theta)$ with a scan speed of $2 \% \mathrm{~min}$.

\section{Results and discussion}

\subsection{Free swelling and settling experiments with bentonite}

\subsubsection{Free swelling experiments}

The results from the free swelling experiments after approximately four weeks, when no further free swelling was observed, are schematically depicted in Fig. 1. The different colors of the diagram bars represent the different bentonite/ $\mathrm{SiO}_{2}$-colloid phases that could be distinguished visually. Small differences can be seen between the different samples but the general trends were (starting from the bottom): A dark bentonite phase consisting of montmorillonite and the accessory minerals was seen in all samples. Above this phase, a more diffuse lighter phase dominated by montmorillonite with or without $\mathrm{SiO}_{2}$-colloids was usually seen. A clear and well-separated white phase, presumably dominated by the white $\mathrm{SiO}_{2}$-colloids could only be seen in two samples (B and C, the highest $\mathrm{SiO}_{2}$-concentrations). The untreated samples (A) showed slightly larger sediment volumes with increasing $\mathrm{SiO}_{2}$ content, which may simply be due to the increase in total mass and volume of the samples. In contrast, the samples subjected to $\mathrm{NaCl}$ addition (sample B and C, final concentration $30 \mathrm{mM}$ ) showed decreasing sediment volumes with increasing $\mathrm{SiO}_{2}$ content, meaning that the $\mathrm{SiO}_{2}$-colloids in combination with high ionic strength slightly decreased the free swelling capacity of the bentonite. The B and C samples also had smaller sediment volumes compared with the corresponding A samples. This suggests that larger or fewer aggregates are formed when $\mathrm{SiO}_{2}$-colloids are added to bentonite at high ionic strength. For samples subjected to dehydration with or without $\mathrm{NaCl}$ addition, complete aggregation of the $\mathrm{SiO}_{2}$-colloids would be anticipated. For these samples no consistent trend in swelling capacity was found, which may reflect the complexity of mixed and aggregating dispersions. All samples subjected to $\mathrm{NaCl}$ addition displayed clear supernatants and well defined mudlines. For samples not subjected to $\mathrm{NaCl}$ addition, the dehydrated samples which were modified by $\mathrm{SiO}_{2}$-colloids (D) displayed more diffuse mudlines compared to the untreated samples, indicating an increase in colloid generation upon $\mathrm{SiO}_{2}$ modification. 


\subsubsection{Sedimentation experiments}

Photographs of the mixed bentonite $/ \mathrm{SiO}_{2}$-colloid dispersions after 1 hour of settling are shown in Fig. 2. In terms of free and structural settling, all the samples prepared at low ionic strength, i.e., the untreated (not shown) and dehydrated dispersions, displayed similar free settling behavior with diffuse mud lines for several weeks. However, dispersions subjected to high ionic strength showed large differences. An increase in $\mathrm{SiO}_{2}$-colloid content drastically increased the contribution of free settling, indicating higher colloidal stability towards ionic strength (diffuse mudlines) or formation of larger aggregates (rapid settling).

The settling experiment was terminated after approx. 1 year. The final sediment volumes are schematically depicted in Fig. 3. For the untreated samples no significant trend in final appearance could be seen. For the dehydrated samples at low ionic strength (D), the increase in sediment volume can be explained by formation of larger aggregates upon desaturation. The $\mathrm{B}, \mathrm{C}$ and $\mathrm{E}$ samples which were all subjected to $\mathrm{NaCl}$ addition displayed clear supernatants and denser final sediment volumes with increasing $\mathrm{SiO}_{2}$-colloid content. This indicates that free settling behavior increases with increasing $\mathrm{SiO}_{2}$-colloid content. For the $\mathrm{F}$ samples, no general trend in sediment volume could be seen. The smaller impact of the $\mathrm{SiO}_{2}$-colloids on the $\mathrm{B}$ and $\mathrm{F}$ samples may have resulted from a less homogeneous mixture of bentonite and $\mathrm{SiO}_{2}$-colloids due to the preceding addition of $\mathrm{NaCl}$, which induces the formation of large bentonite aggregates.

\subsection{Montmorillonite/ $/ \mathrm{SiO}_{2}$-colloid interactions}

In order to verify that mixed particles and aggregates of montmorillonite and $\mathrm{SiO}_{2}$-colloids are formed under high ionic strength treatment or by dehydration, dilute dispersions of homo-ionic Na-montmorillonite and $\mathrm{SiO}_{2}$-colloids were prepared, see Table 2. Fig. 4 shows a photograph of the dehydrated and redispersed $\mathrm{Na}$ montmorillonite/ $\mathrm{SiO}_{2}$-colloid samples, $\mathrm{A}_{1}-\mathrm{E}_{1}$ from table 2, after 1 hour. Note the increasing opacity with increasing amount of $\mathrm{SiO}_{2}$-colloids for the dispersions containing both Na-montmorillonite and $\mathrm{SiO}_{2}$-colloids, indicating larger particle sizes with increasing $\mathrm{SiO}_{2}$ content. Without $\mathrm{Na}$ montmorillonite, large needle-shaped $\mathrm{SiO}_{2}-$ particles in the $\mathrm{mm}$ range were formed (sample to the right).

\subsubsection{Size and concentration measurements using PCS}

The results from the PCS investigation generally revealed large differences between reference samples of both Na-montmorillonite and $\mathrm{SiO}_{2}-$ colloids and the mixed dispersions. Interestingly, the measured PCS count rate for a mixed dispersion consisting of 0.1:0.4 weight-\% Namontmorillonite and $\mathrm{SiO}_{2}$-colloids (6.9 Mcps) was found to be approximately the sum of the corresponding pure dispersions, see the reference samples in Fig. 5. The measured particle size (85 $\mathrm{nm}$ ) was approximately the average (by weight) of each corresponding dispersion. Fig. 5a shows the PCS results from the water-dehydrated and redispersed mixed Na-montmorillonite/ $/ \mathrm{SiO}_{2}-$ colloid dispersions from Fig. 4, along with untreated reference samples of both Namontmorillonite and $\mathrm{SiO}_{2}$-colloids. The most notable effect was an increase in PCS count rate with increasing $\mathrm{SiO}_{2}$-colloid content in the mixed dispersions and a decrease in count rate for the water-dehydrated and pure $\mathrm{SiO}_{2}$-colloid sample compared with its reference. Note the dilution factor for the sample with the montmorillonite: $\mathrm{SiO}_{2}$ ratio of 0.1:0.4 weight-\%. The particle size for samples with a montmorillonite: $\mathrm{SiO}_{2}$ ratio of 0.1:0 and 0.1:0.01 and subjected to $0.3 \mathrm{M} \mathrm{NaCl}$ addition was not stable and exceeded $2 \mu \mathrm{m}$ (Fig. $5 \mathrm{~b}$ and c). Interestingly, the particle size found at higher concentrations of $\mathrm{SiO}_{2}$-colloids was consistently around $800 \mathrm{~nm}$. As with the water-dehydrated samples, the PCS count rate for the samples subjected to high ionic strength increased dramatically with increasing $\mathrm{SiO}_{2}$-colloid content for the mixed dispersions and decreased for pure $\mathrm{SiO}_{2}$-colloid dispersions. Hence, these results indicate that both dehydration and high ionic strength treatment modify montmorillonite. 


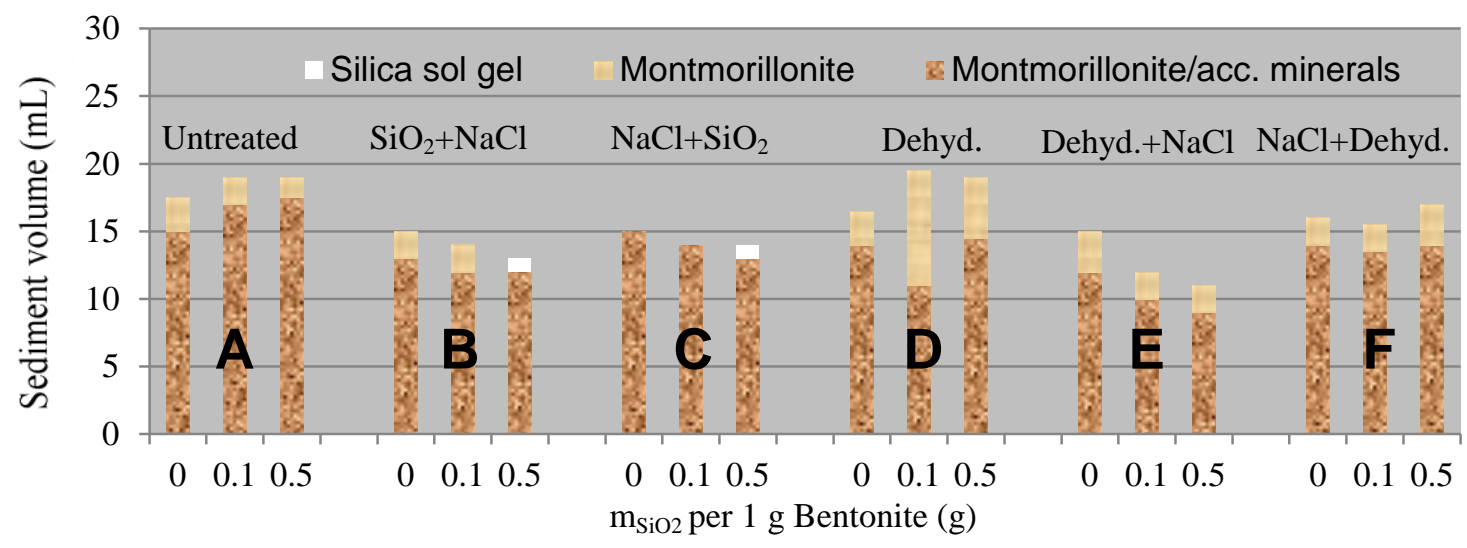

Figure 1. Schematic representation of the final sediment volumes in the free swelling experiment.
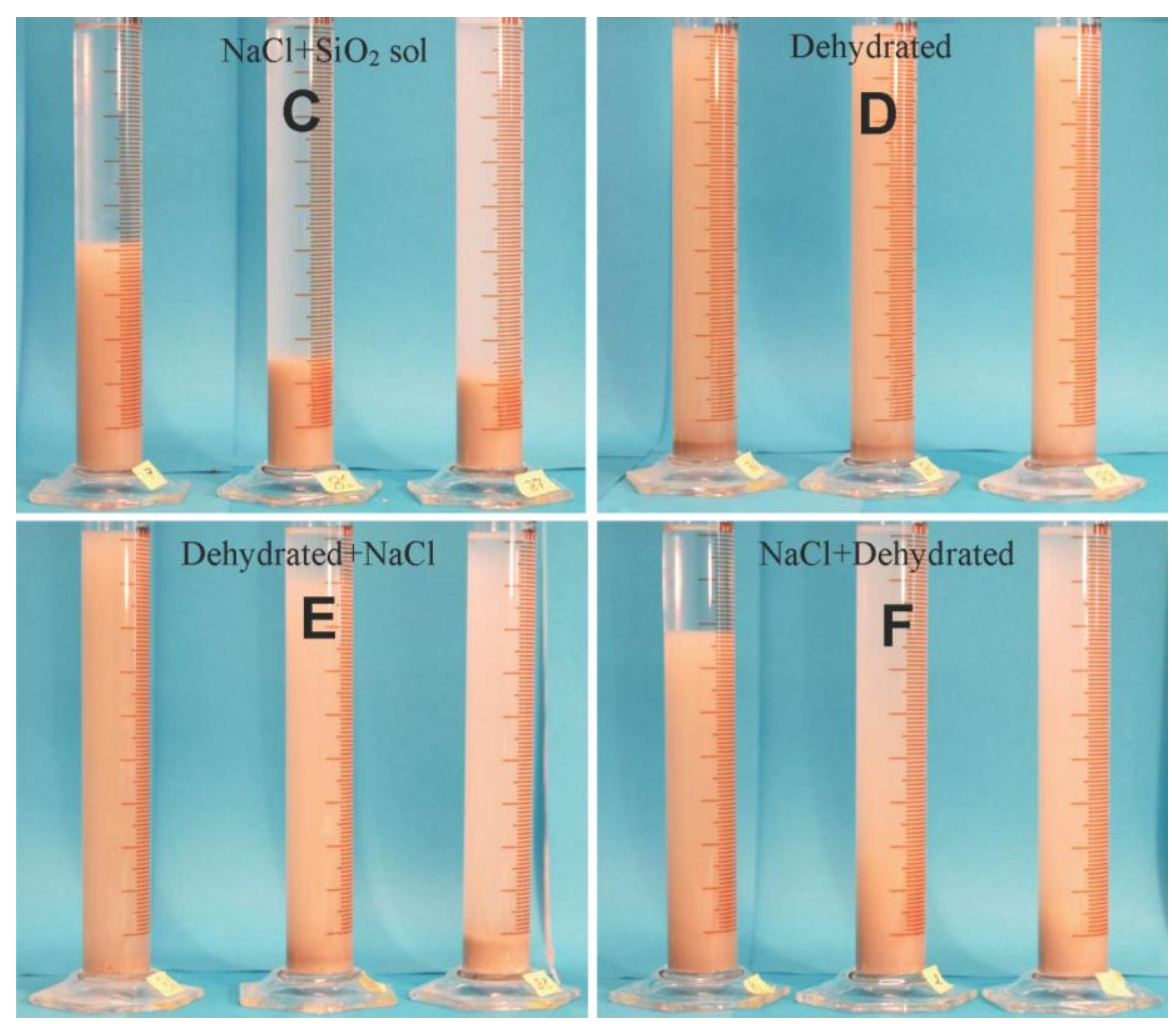

Figure 2. Settling of the mixed Bentonite $/ \mathrm{SiO}_{2}$ colloid dispersions, $\mathrm{t}=1$ hour. $\mathrm{SiO}_{2}$ and bentonite concentrations as in Figure 1 and 3.

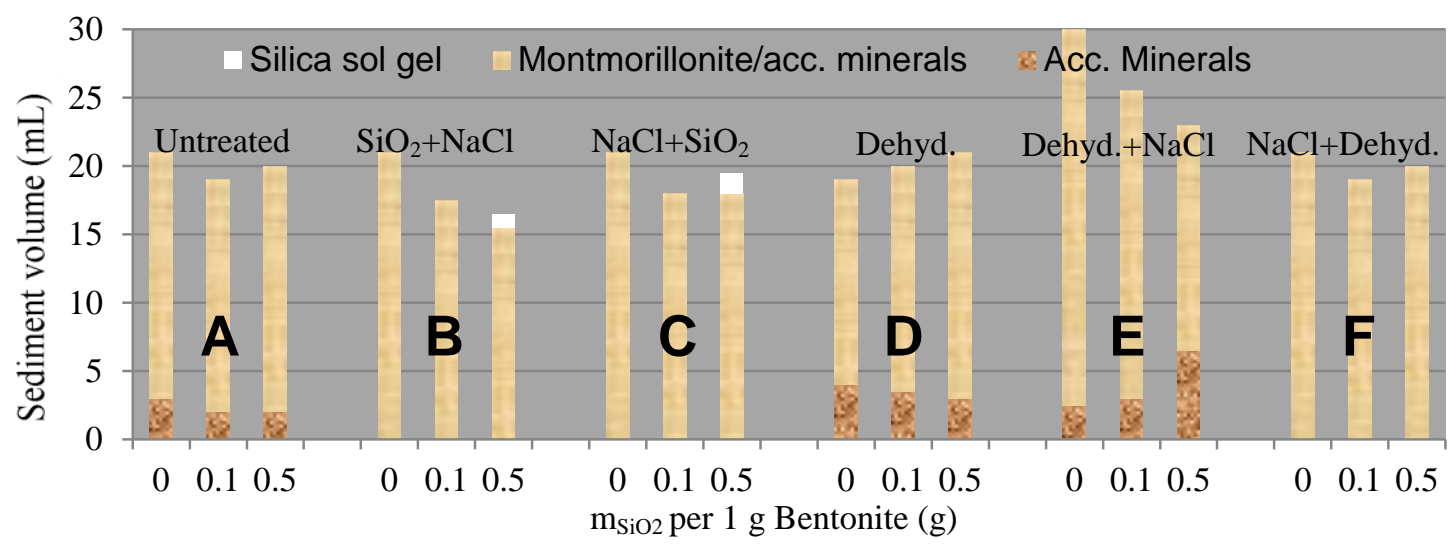

Figure 3. Schematic representation of the final sediment volumes in the settling experiment. 


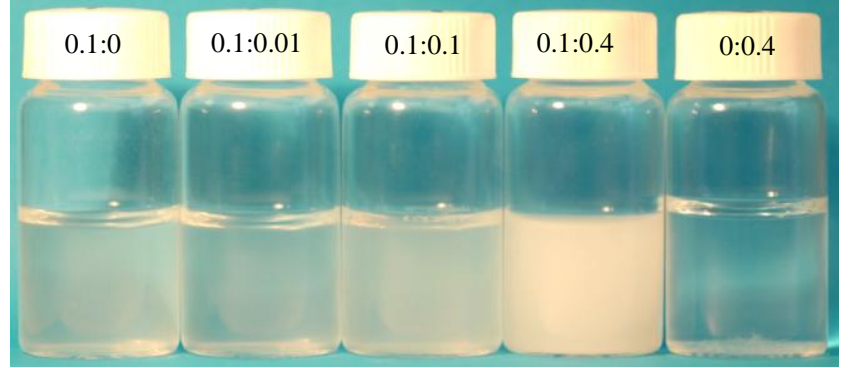

Figure 4. Dehydrated and redispersed Na-montmorillonite $/ \mathrm{SiO}_{2}$-colloid samples, $\mathrm{A}_{1}-\mathrm{E}_{1}$ from Table 2 . The legends denote the weight $\%$ of montmorillonite: $\mathrm{SiO}_{2}$.

\subsubsection{Particle size and elemental analysis with SEM/EDS}

In general, various types of particle shapes and sizes were observed in the SEM investigation, reflecting the polydisperse and heterogeneous character of the samples. Fig. 6 shows a representative SEM image (top image) from the sample with a montmorillonite $/ \mathrm{SiO}_{2}$ ratio of 0.1:0.4, displaying particles of various sizes. The insert image shows an individual particle in the $\mu \mathrm{m}$ size range displaying a flake-like appearance, while the lower image shows rectangular-shaped needles formed by a pure $\mathrm{SiO}_{2}$-colloid dispersion subjected to dehydration. To ensure that the particles formed consisted of both montmorillonite and $\mathrm{SiO}_{2-}$ colloids, the $\mathrm{Al} / \mathrm{Si}$ ratio of selected particles and aggregates (2-3 mappings per sample) was determined by elemental analysis using EDS. From the elemental composition of montmorillonite (Karnland et al., 2006), the theoretical Al/Si ratio for pure montmorillonite was found to be approximately 0.4 . As can be seen, the EDS results (Fig. 7) are in good agreement with the theoretical $\mathrm{Al} / \mathrm{Si}$ ratios. Even though these EDS results may not be representative for the whole particle population due to the heterogeneous character of the samples, they prove that mixed montmorillonite $/ \mathrm{SiO}_{2}$-colloids was formed.
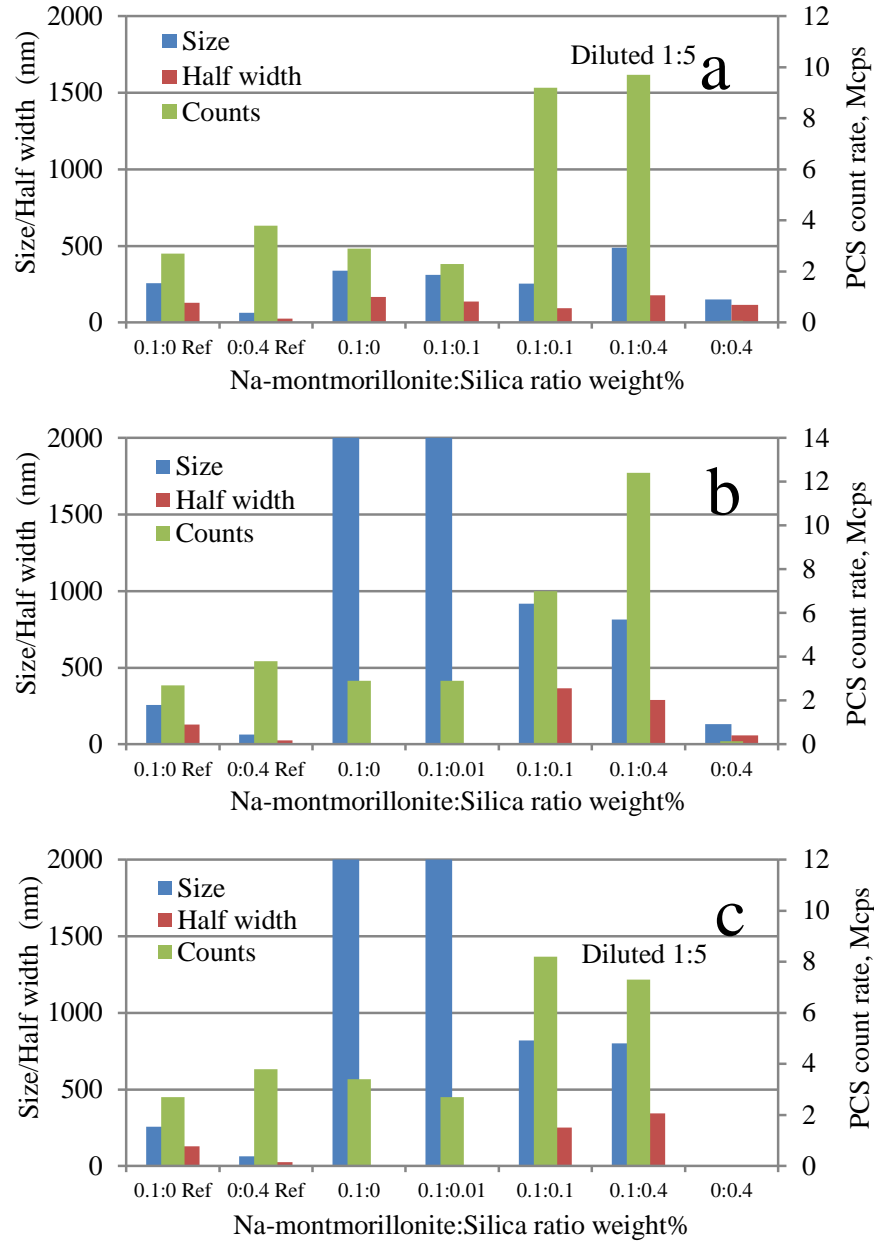

Figure 5. Results from the PCS measurements of mixed Na-montmorillonite/ $\mathrm{SiO}_{2}$-colloid dispersions. a) Water dehydrated and redispersed samples. b) Samples prepared in $300 \mathrm{mM} \mathrm{NaCl}$. c) Samples prepared in $300 \mathrm{mM} \mathrm{NaCl}$ and then water dehydrated and redispersed.

\subsubsection{Montmorillonite/SiO ${ }_{2}$-colloid characterization using AFM}

The main purpose of the AFM investigation was to study initial aggregation of $\mathrm{SiO}_{2}$-colloids with both homo-ionic $\mathrm{Na}$ and Ca-montmorillonite. As with the samples studied with SEM, the AFM investigation revealed a multitude of particles and aggregates of different sizes. Representative images of individual mixed montmorillonite/ $\mathrm{SiO}_{2}$-colloid particles are shown in Fig 8-11. However, in all samples probed both unaggregated montmorillonite and $\mathrm{SiO}_{2}$-colloids were formed to some extent, as well as larger aggregates of mixed particles. A general trend found was that Namontmorillonite particles, unaggregated as well as aggregated, normally consisted of 1-3 montmorillonite layers, whereas $\mathrm{Ca}$-montmorillonite particles with no 
excess $\mathrm{NaCl}$ addition were less exfoliated. For the mixed Na-montmorillonite/ $\mathrm{SiO}_{2}$-colloid dispersions, initial $\mathrm{SiO}_{2}$-colloid attachment occurred preferentially along the edges of the montmorillonite layers.
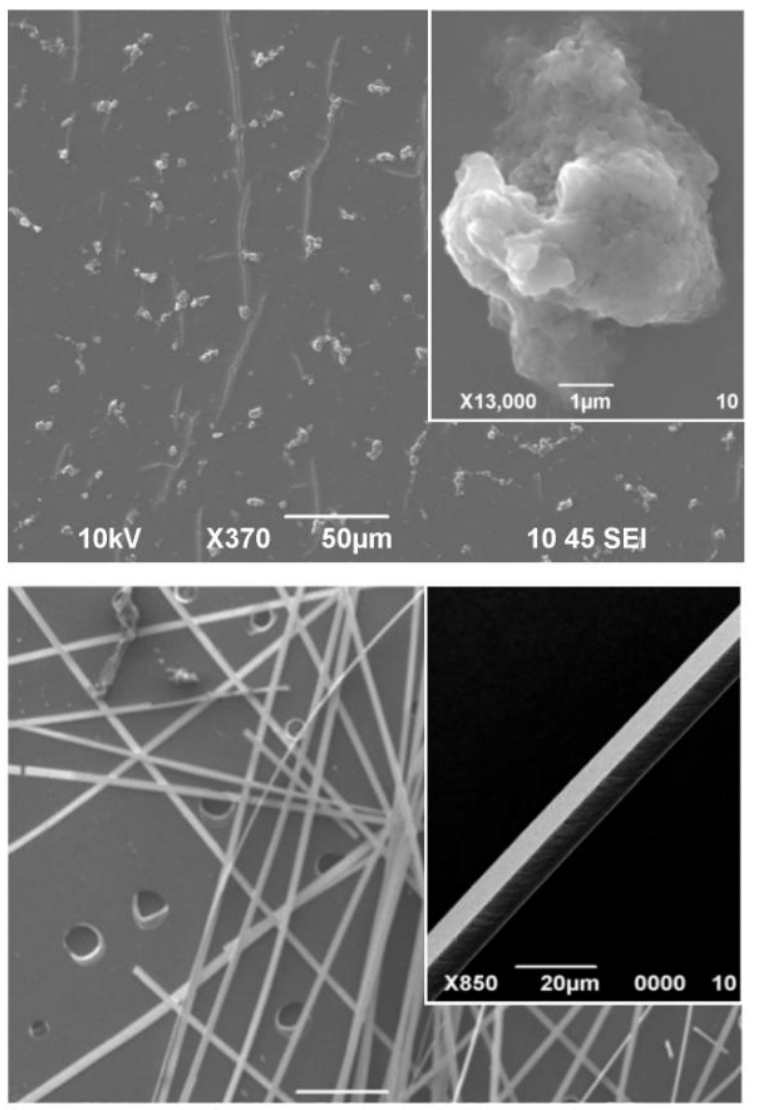

Figure 6. Top image: SEM image of dehydrated Namontmorillonite/ $\mathrm{SiO}_{2}$-colloid sample (0.1:0.4 weight \% when dispersed). Insert shows an individual particle. Lower image: Needles formed by dehydration of $\mathrm{SiO}_{2}$-colloids in the absence of $\mathrm{NaCl}$. The insert show a magnified Silica needle.

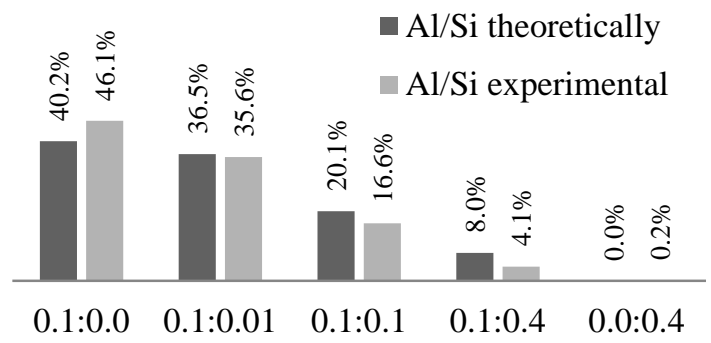

Ratio of montmorillonite:Silica (Weight \%)

Figure 7. Theoretical and experimental $\mathrm{Al} / \mathrm{Si}$ ratios obtained by EDS from the water dehydrated samples in Table 2 . The concentrations of the Na-montmorillonite: $\mathrm{SiO}_{2}$-colloid samples are those of the original dispersions in weight $\%$.
The surfaces of the Na-montmorillonite layers are permanently negatively charged due to isomorphic substitution of $\mathrm{Si}^{4+}$ by $\mathrm{Al}^{3+}$ or $\mathrm{Fe}^{3+}$ in the tetrahedral sheet and of $\mathrm{Al}^{3+}$ by $\mathrm{Fe}^{2+}$ and $\mathrm{Mg}^{2+}$ in the octahedral sheet. Hence, upon attachment of $\mathrm{SiO}_{2}$-colloids on a Namontmorillonite layer, the edges, where similar silanol groups are situated and which do not hold a permanent negative charge, seems to be favored. Upon further attachment of $\mathrm{SiO}_{2}$-colloids to/with the montmorillonite particles, larger $\mathrm{SiO}_{2}$-colloid aggregates were often formed with already attached $\mathrm{SiO}_{2}$-colloids. Shown in Fig. 8a is a representative AFM image from a predehydrated sample displaying Na-montmorillonite particles in various states of aggregation with $\mathrm{SiO}_{2}$ colloids.

For mixed Na-montmorillonite/ $/ \mathrm{SiO}_{2}$-colloid dispersions prepared at high ionic strength $(0.3 \mathrm{M}$ $\mathrm{NaCl}$ ), a similar type of preferential $\mathrm{SiO}_{2}$-colloid attachment onto the montmorillonite particles was generally observed. However for these samples not subjected to pre-dehydration, numerous unaggregated $\mathrm{SiO}_{2}$-colloids were also found (Fig. 9a). This was quite unexpected considering the high $\mathrm{NaCl}$ concentration in these samples and the fact that at the time of the AFM measurements, the samples were approximately 6 months old. Fig. $9 \mathrm{~b}$ and 9c show an individual Na-montmorillonite layer with $\mathrm{SiO}_{2-}$ colloids/aggregates attached along the edges and a height profile of the mixed Na-montmorillonite/ $\mathrm{SiO}_{2}-$ colloid particle. For mixed Ca-montmorillonite/ $\mathrm{SiO}_{2}-$ colloid dispersions subjected to $0.3 \mathrm{M} \mathrm{NaCl}$ addition, a similar preferred mode of attachment was commonly seen as with the mixed Namontmorillonite dispersions (Fig. 10a). This can be explained by ion exchange since the corresponding charge fraction of $\mathrm{Ca}^{2+}$ in montmorillonite under these experimental conditions is estimated to be 1.1$2.3 \%$, using the Gaines-Thomas equation (Gaines and Thomas, 1953) and different $\mathrm{Ca}^{2+} / \mathrm{Na}^{+}$selectivity coefficients (2-5.3) found in the literature (Sposito, 1983a,b, Missana 2007, Birgersson et al. 2009). 


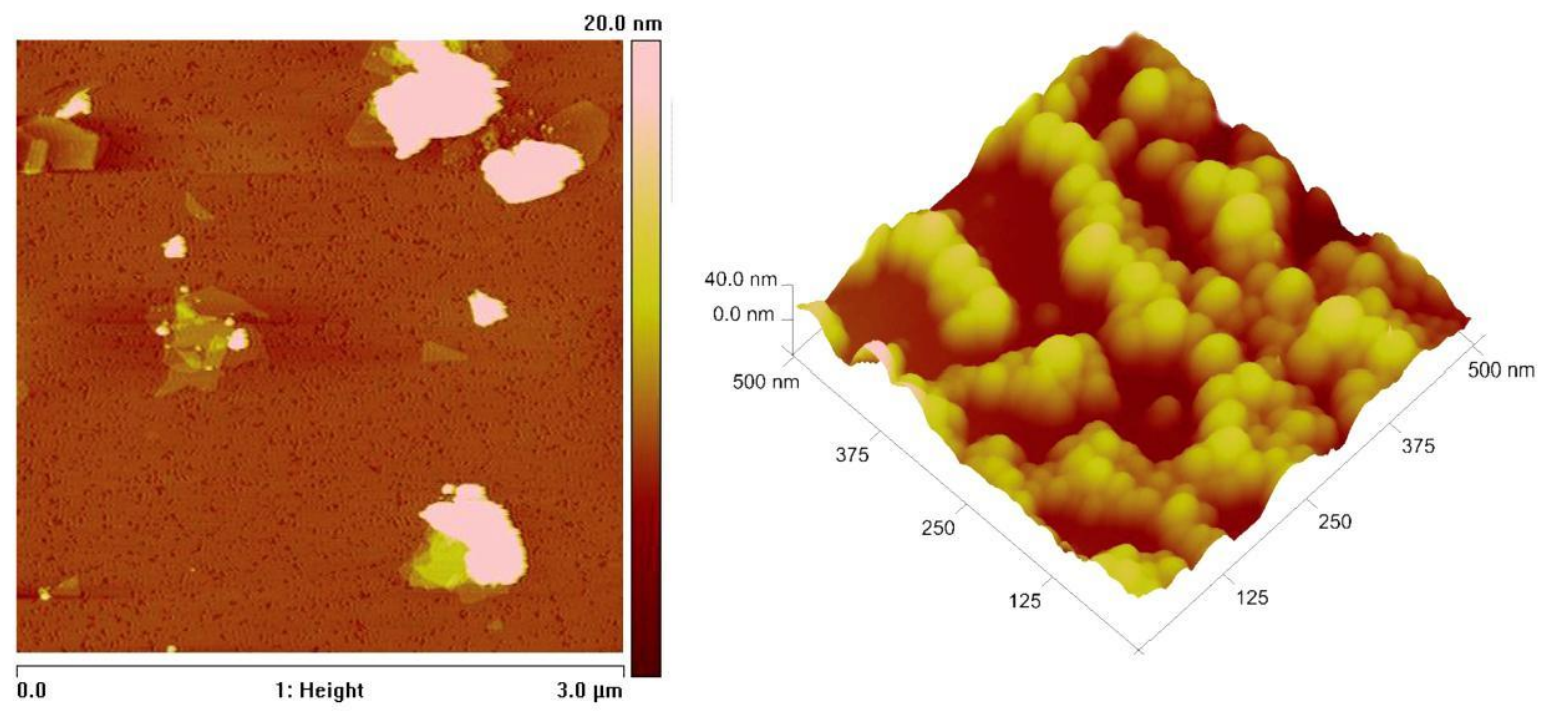

Figure 8. Left image: AFM image (contact mode) of free and mixed particles of Na-montmorillonite/SiO ${ }_{2}$-colloids. Right image: 3D AFM image displaying high concentrations of $\mathrm{SiO}_{2}$-colloids aggregated on a mica surface.

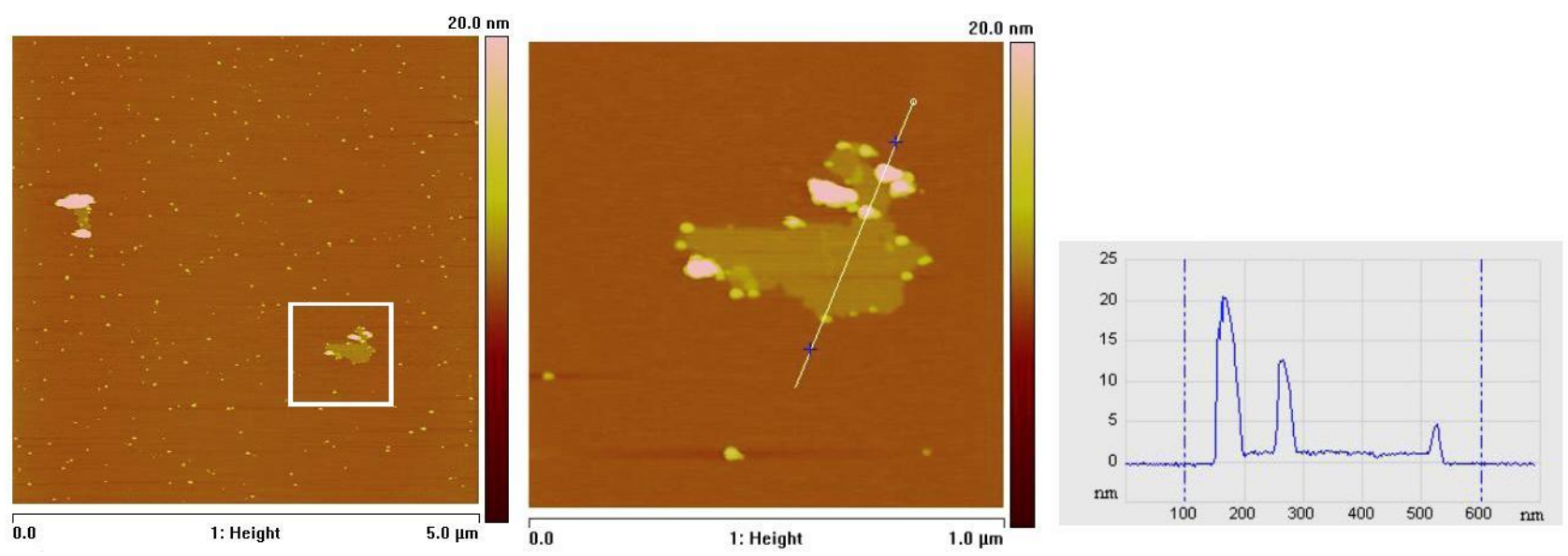

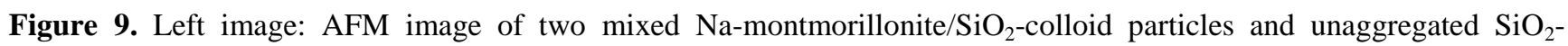
colloids. Middle image: Insert image shows $\mathrm{SiO}_{2}$-colloids sorbed along the edges of a single Na-montmorillonite layer. To the right: Height profile from the insert image.
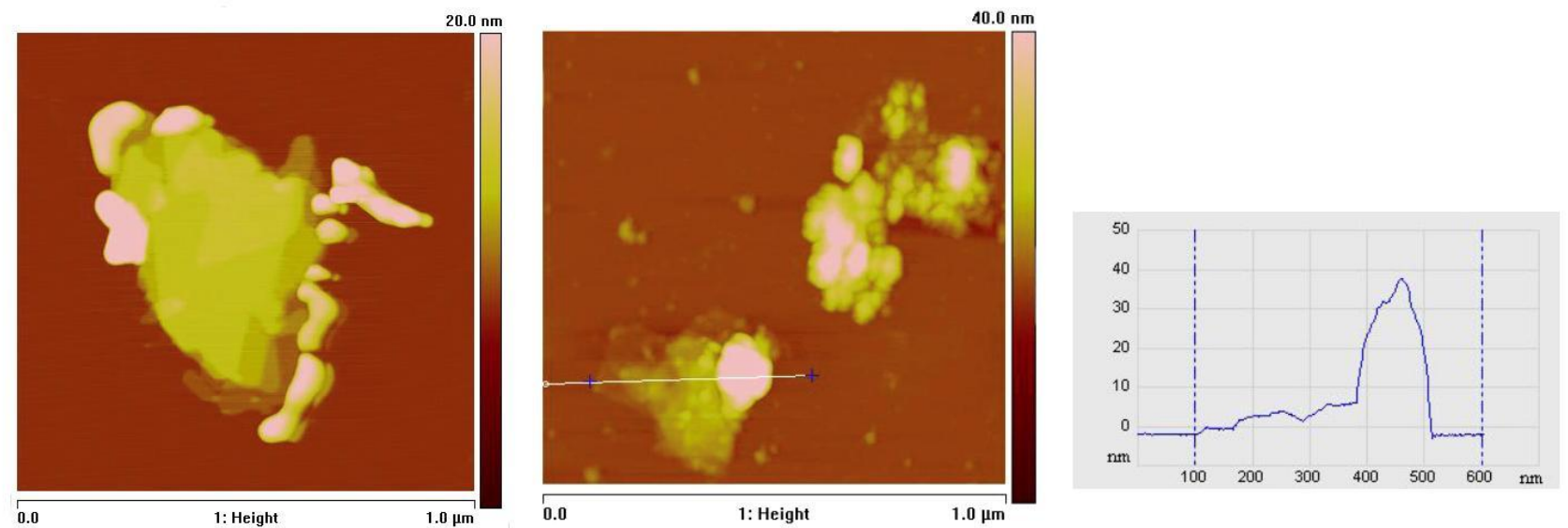

Figure 10. Left image: Sodium exchanged Ca-montmorillonite particle with edge-attached $\mathrm{SiO}_{2}$-colloids from a water dehydrated dispersion containing excess $\mathrm{NaCl}$. Middle image: $\mathrm{Ca}$-montmorillonite particles with face-attached $\mathrm{SiO}_{2}{ }^{-}$ colloids from a dispersion with no excess $\mathrm{NaCl}$. Right image: Height profile from the middle image. 

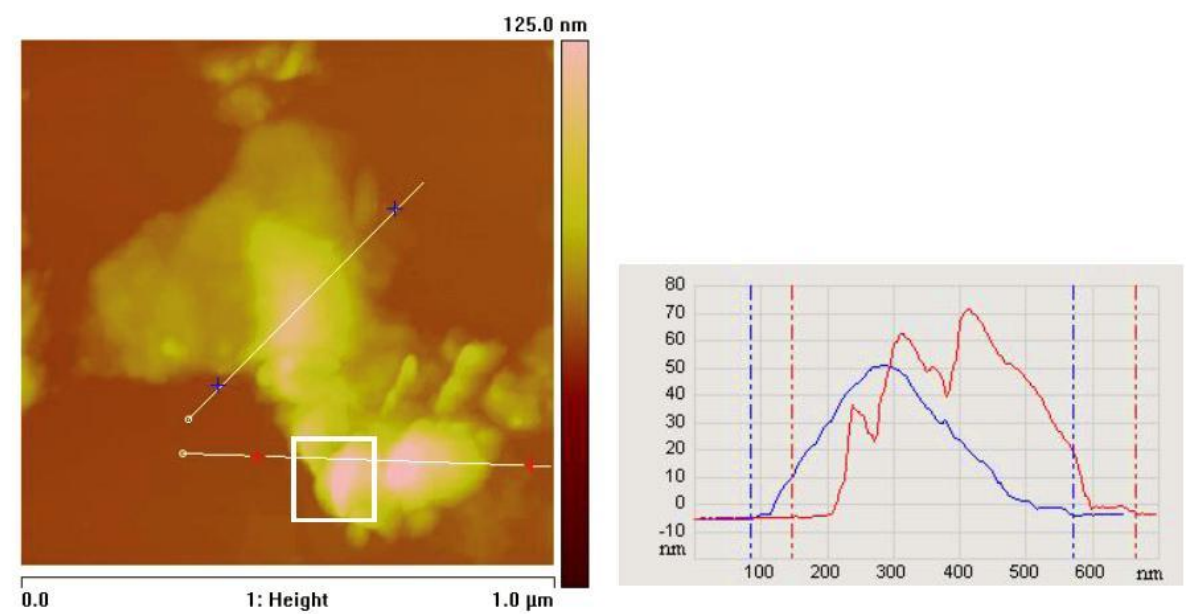

Figure 11. Left image: Large AFM image of Ca-montmorillonite particle covered by $\mathrm{SiO}_{2}$-colloids. Right image: The corresponding height profile.

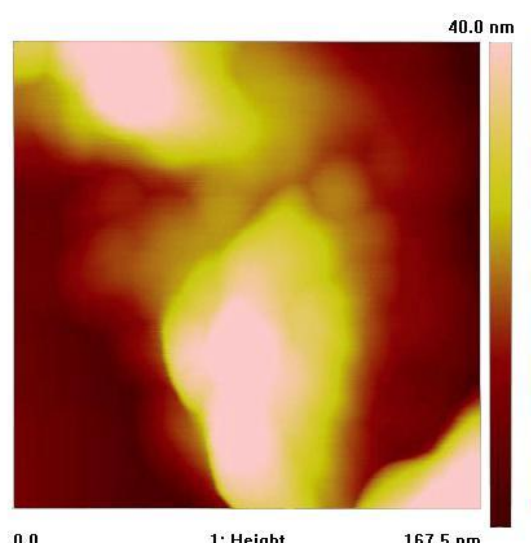

1: Height

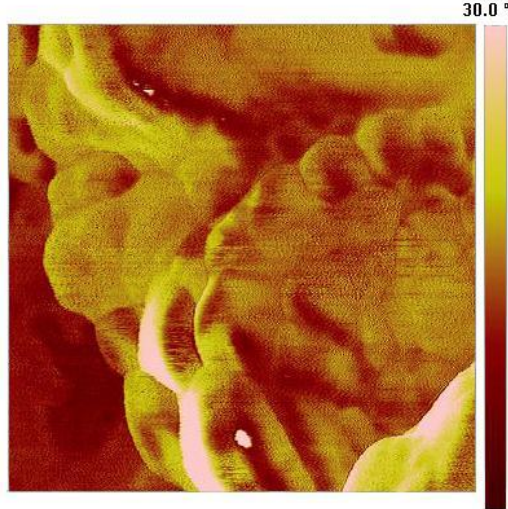

3: Phase

30.0

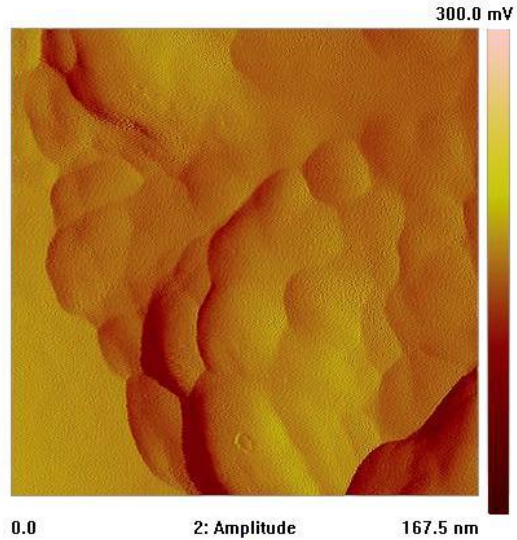

Figure 12. Magnified height, phase and amplitude AFM images (from left to right) from the white square in Fig. 11.

In samples prepared with Ca-montmorillonite that were pre-dehydrated and not subjected to $\mathrm{NaCl}$ addition, the Ca-montmorillonite particles were frequently either entirely or mainly covered by $\mathrm{SiO}_{2}-$ colloids, resulting in relatively large mixed particles, see height profiles in Fig. 10 and 11. This indicates that $\mathrm{Ca}^{2+}$ induces montmorillonite face aggregation of the $\mathrm{SiO}_{2}$-particles. The $\mathrm{SiO}_{2}$-colloid particles in the samples containing Ca-montmorillonite usually appeared less resolved than those in samples containing Na-montmorillonite, possibly due to larger height differences in the Ca-montmorillonitecontaining samples. Fig. 12 shows a magnified height, phase and amplitude image from the AFM height image in Fig. 11, displaying a globular surface. The different preferred mode of attachment of the $\mathrm{SiO}_{2}$-particles on Na-montmorillonite and $\mathrm{Ca}$ montmorillonite respectively, may be explained by the greater ability of $\mathrm{Ca}^{2+}$ to form bridging electrostatic bonds between the negatively charged surfaces compared to $\mathrm{Na}^{+}$. According to Iler (Chp. 4, 1979) this is because sorption of $\mathrm{Ca}^{2+}$ on a hydroxylated $\mathrm{SiO}_{2}$-surface only replaces one proton per $\mathrm{Ca}^{2+}$ ion, leading to a localized positive surface charge. Another explanation could perhaps be the ion-ion correlation forces and fluctuations in the ionic clouds proposed for divalent ions in lamellar systems reported by Guldbrand et al. (1984) and Kjellander and Marčelja (1988).

\subsubsection{Basal spacing measurements using PXRD}

The PXRD tracings from bentonite samples dehydrated with varying amounts of $\mathrm{SiO}_{2}$-colloids are shown in Fig. 13. In the low angle region, clear and broad $d_{001}$ peaks at $5.75^{\circ} 2 \theta$ were seen for all bentonite samples. This diffraction peak corresponds 
to an average basal spacing of $15.4 \AA$, resulting from a hydrated state of the montmorillonite interlayer consisting mainly of two water layers (Norrish, 1954, Ferrage et al. 2005). The higher order $00 l$ peaks at higher angles were very weak. Thus no significant change in the 001 peaks upon increasing $\mathrm{SiO}_{2}$ content could be found, except decreasing total intensity. This means that the $\mathrm{SiO}_{2}$-colloids do not alter the interlayer distances in the bentonite. Increasing $\mathrm{SiO}_{2}$ content resulted in a broad amorphous peak situated around $22-23^{\circ} 2 \theta$. Furthermore, for the pure $\mathrm{SiO}_{2}$ colloid samples, no diffraction peak due to crystalline $\mathrm{SiO}_{2}$ at $26.65^{\circ} 2 \theta$ (not shown) could be found, proving that the $\mathrm{SiO}_{2}$-colloids are highly amorphous.

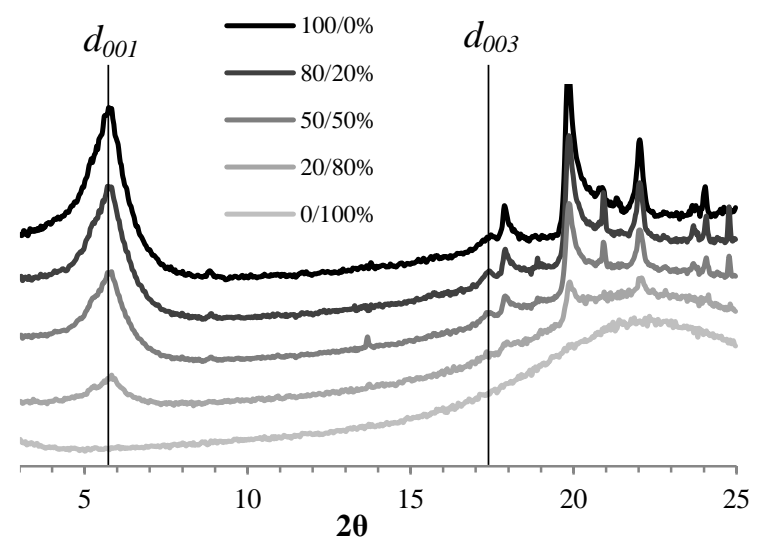

Figure 13. PXRD tracings of dehydrated Bentonite/SiO ${ }_{2}^{-}$ colloid samples. The Bentonite: $\mathrm{SiO}_{2}$ weight ratios are shown in $\%$.

\subsection{Summary and conclusions}

In recent years many colloid-related issues have generated a lot of interest in the context of deep geological repositories for nuclear waste. Silica sol, i.e., colloidal $\mathrm{SiO}_{2}$, may be used as an injection grout in the excavation and construction of deep geological repositories for radioactive waste in Sweden as well as in Finland. If the $\mathrm{SiO}_{2}$-colloids would aggregate heterogeneously and irreversibly with bentonite and specifically the montmorillonite particles, there is concern that the properties of bentonite at the bentonite/bedrock interface might be affected. In this study several qualitative experiments were performed with mixed dispersions of $\mathrm{SiO}_{2}$-colloids and bentonite or homo-ionic $\mathrm{Na} / \mathrm{Ca}$-montmorillonite, prepared under various conditions such as high ionic strength $(0.3 \mathrm{M} \mathrm{NaCl})$, dehydration and varying $\mathrm{SiO}_{2}$-colloid concentrations. The free swelling experiments with bentonite indicate that unaggregated silica sol, i.e., $\mathrm{SiO}_{2}$-colloids, under certain conditions can affect bentonites swelling capacity. In the settling experiment an increase in free settling behavior over structural settling was generally observed which indicates that the montmorillonite particles increase in size or gain increased colloidal stability towards ionic strength upon aggregation with $\mathrm{SiO}_{2}$-colloids. Probing with EDS in the SEM investigation confirmed that large mixed montmorillonite/ $\mathrm{SiO}_{2}{ }^{-}$ colloid particles are formed. The PCS measurements also indicate that $\mathrm{SiO}_{2}$-colloids modify bentonite under both dehydration and high ionic strength conditions. For both dehydrated or high ionic strength treated samples no measurable difference was found when a small amount (10\% by weight) of $\mathrm{SiO}_{2}$ colloids relative the amount of montmorillonite were added, in either size or count rate. However further addition of $\mathrm{SiO}_{2}$-colloids resulted in drastically higher PCS count rates in all samples. This can only be explained by the formation of larger mixed particles, which also was seen in the SEM investigation. From the AFM investigation it was found that the preferred initial mode of attachment for Na-montmorillonite samples seems to be $\mathrm{SiO}_{2}$-colloid-montmorilloniteedge sorption. However for Ca-montmorillonite samples with no excess $\mathrm{NaCl}$ added, $\mathrm{SiO}_{2}-$ colloid/montmorillonite-face attachment was found. From the PXRD investigation of mixed bentonite and $\mathrm{SiO}_{2}$-colloid samples, no difference in interlayer distances could be found. This indicates that attachment and $\mathrm{SiO}_{2}$-colloid sorption occurs on the extralamellar surfaces on the montmorillonite particles.

The results from this study show that bentonite and montmorillonite particles can be modified by $\mathrm{SiO}_{2}-$ colloids when mixed in comparable amounts (by weight) under dehydration or high ionic strength (0.3 $\mathrm{M} \mathrm{NaCl}$ ). Some indications of increased colloidal stability for the $\mathrm{SiO}_{2}$-colloid modified clay particles were also found. Because of this it is suggested that contact between ungelled Silica sol and the bentonite barrier in the future deep geological repositories for radioactive waste in Sweden and in Finland is to be avoided.

In order to further assess the effects on $\mathrm{SiO}_{2}$-colloids on bentonite in future work, more quantitative colloid 
stability experiments should be performed, preferably with better characterized and monodisperse montmorillonite and $\mathrm{SiO}_{2}$-colloids, or perhaps other colloid analogues. Also, further tests on changes of the physical properties such as swelling pressure and rheology should be performed.

\section{Acknowledgements}

Acknowledgement: SKB (The Swedish Nuclear Fuel and Waste Management Co.) is gratefully acknowledged for financial support.

\section{References}

Birgersson, M., Börgesson, L., Hedström, M., Karnland, O., Nilsson, U., 2009. Bentonite erosion - Final report. SKB Technical report, TR-09-34.

Bodén, A., Sievänen, U., 2005. Low-pH injection grout for deep repositories, SKB report R-05-40/Posiva Report WR 2005-24.

Emmelin, A., Brantberger, M., Eriksson, M., Gustafson, G., Stille, H., 2007. Rock grouting: Current competence and development for the final repository. SKB Report, R07-30.

Ferrage, E., Lanson, B., Sakharov, B.A., Drits, V.A., 2005. Investigation of smectite hydration properties by modeling experimental X-ray diffraction patterns: Part I. Montmorillonite hydration properties. Am. Mineral. 90, 1358-1374.

Funehag, J., 2008. Injektering av TASS-tunneln. SKB report, R-08-123. Written in Swedish.

Gaines, G.L., Thomas, H.C., 1953. Adsorption studies on clay minerals. II. A formulation of the thermodynamics of exchange adsorption. J. Chem. Phys. 21, 714-718.

Gunnarsson, I., Arnórsson, S., 2000. Amorphous silica solubility and the thermodynamic properties of $\mathrm{H}_{4} \mathrm{SiO}_{4}$ in the range of $0^{\circ}$ to $350^{\circ} \mathrm{C}$ at $\mathrm{P}_{\text {sat }}$. Geochim. Cosmochim. Acta., 64(13), 2295-2307.

Guldbrand, L., Jönsson, B., Wennerström, H., Linse, P., 1984. Electrical double layer forces. A Monte Carlo study. J. Chem. Phys., 80(5). 2221-2228.

Lee, H.J., Moon, S.H., 2004. Influences of colloidal stability and electrokinetic property on electrodialysis performance in the presence of silica sol. J. Colloid Interface Sci., 270, 406-412.

Hölttä, P., Hakanen, M., Lahtinen, M., Leskinen, A., Lehto, J., Juhola, P., 2009. Release of Colloids from Injection Grout Silica Sol. Mater. Res. Soc. Symp. Proc., 1124-Q10-14.
Hölttä, P., 2008. Silica Colloids and their Effect on Radionuclide Sorption - A Literature Review. Posiva Working Report 2008-29.

Iler, R.K., 1979. The Chemistry of Silica. John Wiley \& Sons, New York.

Karnland, O., Olsson, S., Nilsson, U., Sellin, P., 2007. Experimentally determined swelling pressures and geochemical interactions of compacted Wyoming bentonite with highly alkaline solutions. Phys. Chem. Earth., 32, 275-286.

Kinsela, A.S., Tjitradjaja, A., Collins, R.N., Waite, T.D., Payne, T.E., Bennett C.T. Macdonald, B.C.T., White, I., 2010. Influence of calcium and silica on hydraulic properties of sodium montmorillonite assemblages under alkaline conditions. J. Colloid Interface Sci., 343, 1, 366373.

Kjellander, R., Marčelja, S., Pashley, R.M., Quirk, J.P., 1988. Double-Layer Ion Correlation Forces Restrict Calcium-Clay Swelling. J. Phys. Chem., 92, 6489-6492.

Missana, T., García-Gutiérrez, M., 2007. Adsorption of bivalent ions $(\mathrm{Ca}(\mathrm{II}), \mathrm{Sr}(\mathrm{II})$ and $\mathrm{Co}(\mathrm{II}))$ onto FEBEX bentonite. Phys. Chem. Earth., 32, 559-567.

Moore, D., Reynolds, R.C., 1997. X-Ray Diffraction and the Identification and Analysis of Clay Minerals. 2nd Ed, Oxford University Press.

Neretnieks, I., Liu, L., Moreno, L., 2009. Mechanisms and models for Bentonite Erosion, SKB Technical report, TR09-35.

Norrish, K., 1954. The swelling of montmorillonite. Disc. Faraday Soc., 18, 120-134.

Sposito, G., Holtzclaw, K.M., Charlet, L., Jouany, C., Page, A.L., 1983a. Sodium-calcium and sodiummagnesium exchange on Wyoming bentonite in perchlorate and chloride background ionic media. Soil Sci. Soc. Am. J., 47, 51-56.

Sposito, G., Holtzclaw, K.M., Jouany, C., Charlet, L., 1983b. Cation selectivity in sodium-calcium, sodiummagnesium, and calcium-magnesium exchange on Wyoming bentonite at 298 K. Soil Sci. Soc. Am. J., 47, 917-921. 